\title{
Adenocarcinoma of the liver and intrahepatic biliary tract
}

INSERM

\section{Source}

INSERM. (1999). Orphanet: an online rare disease and orphan drug data base. Adenocarcinoma of the liver and intrahepatic biliary tract. ORPHA:424943

A very rare hepatic and biliary tract tumor characterized by a growth pattern ressembling that found in hepatocellular carcinomas and cholangiocacinomas but presenting atypical histological and immunohistochemical features (such as trabecular, organoid, microcystic and/or blastemal-like architecture and inhibin A, cytokeratin 7 and/or cytokeratin 19 positivity) that do not allow a formal diagnosis of the more common aforementioned liver cancers. Patients may present adbominal distension and pain, a palpable abdominal mass and elevated liver enzymes. 